\title{
Teaching Reform Discussion with the Center of Students and based on Case Teaching Method
}

\author{
J. H. SU, F. WANG \& B. GUO \\ School of Electronic and Information Engineering, Changchun University of Science and Technology, \\ Changchun, Jilin, China
}

\begin{abstract}
Chinese current teaching method with the center of teachers, the foreign teaching with the center of students is a kind of teaching method with more science and more accept by students. The article explains the new teaching method with the tool of teaching and the center of students from the three ways of background, basis and execution method of teaching method reform. The kind of teaching method embodies the education concept of "basing on people" and is a reliable selection when we face the global new opportunity and want to attain advantages in the new period.
\end{abstract}

KEYWORD: case teaching; the center of students; teaching reform

\section{BACKGROUND OF TEACHING METHOD REFORM}

\subsection{Improvement of Social Requirement}

In nowadays of rapid technology development, we often hear "the quality of undergraduates is worse and worse". The reason is the progress of society and technology and we have higher and higher requirement for the students with senior education. As an example of internet, twenty years ago, the students possibly have blank expression when they hear the word, but the nowadays with developed information, if you aren't familiar with the internet, it is difficult for you to attain the newest information and attain first opportunity. The modern society asks us to culture the students capable of finding problems, thinking promptly and positively innovating [1]. The students lack these capabilities under the current education system. The three times of science and technology revolutions tell us a fact also: the countries mastering the newest science and owning innovative spirit will be glory on the world [2].

\subsection{Backward of Teaching Method}

Chinese universities currently mostly adopt the typical teaching method after the twentieth century "teaching method". This kind of teaching method centralizes with the teachers. In the classroom and experiment teaching guided by the thinking, the students as a main part always are in a subordinate position and passively accept knowledge. The various multi-media teaching methods strengthen the process also [3-4]. Obviously this kind of traditional teaching method ignores the students' main role in the study. There lacks communication between the students and the students and teachers. The students' characteristics development is restrained and obstacle which is not favorable to culture the students' innovative thinking and solving capability.

\subsection{Refer for the Foreigners}

Study the foreign advanced education concept can introduce new activity and motion for our country. It cannot be said that "teaching method" has an obvious effect at the beginning of formation and cultures a team of intellectuals. But with the social progress, this kind of teaching method can't meet with the social need for the intellectuals and it is necessary to be substituted by the scientific teaching method. After reform and opening, more science and concepts are introduced to China. As a kind of new teaching reform form, the intellectuals culturing teaching method with the center of students from the western universities is introduced China. The method can better motivate the students' positivity and culture the students' autonomy.

\section{REFERENCE OF TEACHING METHOD REFORM}

\subsection{Teaching method reform is a kind of necessary trend}

"Lots of small boats go smoothly the sunken boats and there is lots of green forest in the front of the 
bad trees". The old things always will be substituted by the new things, which is the necessary selection of history. Economy, life and science and technology meet with the reform. Now, the reform of education area no longer is the refresh word. Only reform and innovation can pour refresh blood for Chinese education [5].

\subsection{Implementing teaching method reform received good effect}

As an experiment objective of the lesson "single machine principle and application", after it implements the teaching reform proposal with the tool of case teaching, it finds the students' study interest for the lesson rise greatly, the lesson atmosphere becomes active, and also finds they have better understanding for the corresponding experiment lesson, can put forward more and more innovative problems, can solve most of the problems through autonomous study. Their test achievements are better than the former students and the student quantity of the second year rises greatly.

\subsection{Mutual Imitation between Schools}

There exists imitation between the schools. The junior colleges do their best to keep consistence with the universities with fame and level. There exists this situation between the teachers. When one teacher's teaching method attains affirmation, the other teachers will imitate and more and more teachers use new teaching method, which will bring the lesson's teaching method reform, thus there exists a kind of butterfly effect. So among the "985" universities, the new teaching method with the center of students and combining with case teaching, will radiate for the surrounding schools. The increment of the participant teachers will introduce this method to the other science area and this will change the fatigue of Chinese current education.

\section{IMPLEMENTATION METHOD OF TEACHING METHOD REFORM}

\subsection{Case Design and Teacher Guidance}

The teachers should carefully design the teaching cases according to the lesson contents and speak out the theoretical contents through the case guidance and with multi-media and internet design and through point to platform, motivate the students' study interest and improve study efficiency [6]. In every case, the students are the study subject, can mutually discuss, ask for the teachers, utilize internet resource and solve the study problems from lots of aspects and ways. The students mutually study, mutually inspire, produce new thinking and experience team strength in the discussion.
The success and failure of the teaching method application with the center of the students and basing on case teaching method, greatly depends on the teacher guidance. Firstly if the teachers guide badly, the decision factor of the effective implementation of teaching method become the students' intelligence level and comprehensive factor; secondly because the case teaching method efficiency is low, if the subjects the teachers give can't be clear and correct, the teaching efficiency will drop, the most time of one lesson being occupying by lectures and questioning is the typical example of wrong using case teaching method. So the subject the teachers give should master one "degree'. According to the students' whole level, it should be reasonable questioning.

\subsection{The students group and motivate the study positivity}

In the traditional "teaching" method, the big lesson lacks communication and can't motivate the students' study positivity. The small lesson can decrease this kind of shortage, but it need add the teachers' strength [7]. The grouping cooperation compensates with their shortage. This kind of method not only cultures the students' communication capability, but also improves the students' expression capability, sufficiently motivates the students' positivity and has the students attain new thinking in communication. Additionally the students will learn the things' role should be played sufficiently and the capability should be played out during the division and cooperation.

\subsection{Emphasizing Experiment and Culturing Innovative Capability}

The experiment lesson is the process that the students have identification, understanding and simple design with their knowledge. In contrast with the lesson, the experiment teaching can provide an autonomous and innovative environment for the students. Especially when design experiment, the students have analysis and discussion for the design subject and put forward their owned opinions with the former grouping. The process can sufficiently play the students' subjective initiative, not only think over the learned knowledge, but also produce innovative thinking and culture the students' capability of investigation and research, documentation consultation, analysis and argument, proposal making, design experiment and analysis and summary.

\subsection{Utilizing Internet and Improving Efficiency}

The internet application breaks out the traditional 
time limitation of lesson. The students not only can have timely communication with the teachers and the students can have communication and study mutually. This shortens the distance between people and provides good learn platform. The students can choose communication time, confirm communication contents and replace communication method according to their owned situation. For example, the teachers can utilize internet to periodically hold video discussion with the students and compensate with the shortage of lesson teaching time. The internet application realizes the opening and timing of communication. In communication, the students check out the shortage, open the insight, inspire the study interest, improve the study motivation and possibility of the students and realize the teaching concept of "centralizing with the students" promptly [8].

\section{SUMMARY}

Volm, American Scholar, once said the students aren't the competitive commodity on market and it is better to call the students as "learners". The new teaching method introduces the students to autonomous study with the tool of case and the center of students, inspires the study motivation and cultures the operation capability. This kind of teaching method sufficiently embodies the main position of the students and the main role of the teachers, and the teaching effect is good. So we should positively abandons the traditional teaching method, start to apply and adapt to new teaching method, develops the students' characteristics and advantages and culture intellectuals for the countries to meet with new times need. Of course, this way has disadvantage to improve and will become a mature teaching method through times of practice and application.

\section{REFERENCES}

[1] Tan Xiaoqian. 2010. From experiment class to Yuanpei College. China Science Innovation Magazine.

[2] Wang Xiangxiu. 2013. American Law Case Teaching Method and Its Inspiration for China. Professional Time and Space (03).

[3] Wu Gaohui. \& Yang, Taozhao. \& Xiwen etc. 2002. Structure and practice of undergraduate innovation spirit and practice capability culturing system. Senior Engineering Education Research (3): 21-23.

[4] Li Jiazeng. 2000. Foreign Senior Engineering Education Reform Trend Summary. Electric and Electronics Teaching Paper 22(3): 8-10.

[5] Yang Lei. 2008. American Undergraduates Affairs Management to Promote Characteristics Development of Students. Northeast Teacher University.

[6] Li Jiawang. 2005. Example Research Method's Application in Teaching. Guangxi Agriculture Mechanization (5):24-25.

[7] Kang Quanli. 2011. Chinese College Bachelor Education Concept and Teaching Reform Research. Qingdao: Ocean University of china.

[8] Liu Guoguang. 2004. Task Driving Method's Application in Single-chip Machine Teaching. Senior Education Research Paper 27(4): 74-75. 